\title{
THE GENESIS OF APPROACHES TO UNDERSTANDING THE CONTENT OF THE CREDIT RECOVERY ARRANGEMENT OF BANKING LOANS
}

\author{
Kira V. Smetanina \\ Saratov Socio-Economic Institute (Branch) of Plekhanov Russian University of Economics, \\ Saratov, Russian Federation
}

\begin{abstract}
The relevance of this scientific paper is conditioned by existence in Russia of sharp problem of credit relations development, related to the high stake debt on the loans given out by banks. Along with undoubted meaningfulness of searches for solution of the indicated problem in practice, the subjects of providing of collectability of credits suppose the necessity of deep research in the theory of this question. To that end, we summarize and compare the approaches of different Russian scientists, engaging in the modern range of problems of credits collectability. As a result, we prove that all authors tie up such bases with the opening of concepts 'Mechanism of providing credits collectability', 'form of provision', 'methods of provision', 'methods of extinguishing' and 'sources of credit extinguishing'. That substantial differences take place both in relation to understanding of value of these terms and their rich description. With the purpose of systematization and disarticulation of approaches of different scientists, we present a table expounding key positions in each of the viewpoints.

Summing up the analysis of the evolution of contradictory views of Russian scientists on the conceptual mechanism of security mechanisms of bank loans repayment, we have attempted to highlight those issues on which a certain unity of opinions has been reached and which can serve as a starting point for further in-depth study of the scientific foundations for the effective use of guarantee-pledge mechanisms in bank lending.

Key words: loan, credit recovery, credit recovery mechanism, forms of provision, sources of bank repayment, techniques of paying loans, ways of paying loans, past-due indebtedness.
\end{abstract}

УДК 336.77

ББК 65.262 .2

\section{ГЕНЕЗИС ПОДХОДОВ К ПОНИМАНИЮ СОДЕРЖАНИЯ МЕХАНИЗМА ОБЕСПЕЧЕНИЯ ВОЗВРАТНОСТИ БАНКОВСКИХ КРЕДИТОВ}

\author{
Кира Владимировна Сметанина \\ Саратовский социально-экономический институт (филиал) Российского экономического университета \\ им. Г.В. Плеханова, г. Саратов, Российская Федерация
}

Аннотация. Актуальность научной статьи обусловлена существованием в России острой проблемы развития кредитных отношений, связанной с высокой долей просроченной задолженности по выданным банками ссудам. Наряду с несомненной значимостью поисков решения указанной проблемы на практике, тематика обеспечения возвратности кредитов предполагает необходимость углубленных исследований и в теории вопроса. С этой целью в статье обобщаются и сопоставляются подходы различных российских ученых, занимавшихся современной проблематикой обеспечения возвратности кредитов.

В результате последовательного анализа существующих в отечественной науке точек зрения относительно научных основ обеспечения возвратности кредита в статье доказывается, что все авторы, так или иначе, увязывают таковые основы с раскрытием понятий «механизм обеспечения возвратности кредита», «форма обеспечения», «способы обеспечения», «методы гашения» и «источники гашения кредита». При этом имеют место существенные отличия как относительно понимания разными автора- 
ми значения данных терминов, так и их содержательной характеристики. Для наглядности восприятия и с целью систематизации и вычленения основного в подходах различных ученых в статье представлена таблица, излагающая ключевые положения в каждой из точек зрения.

Подводя итог рассмотрению эволюции противоречивых взглядов отечественных ученых на понятийный аппарат обеспечительных механизмов возвратности банковских ссуд, в статье предпринимается попытка выделить те моменты, по которым достигнуто определенное единство мнений, и, которые могут послужить отправной точкой для дальнейшего углубленного исследования научных основ эффективного использования гарантийно-залоговых механизмов в банковском кредитовании.

Ключевые слова: кредит, возвратность кредита, механизм обеспечения возвратности, формы обеспечения, источники гашения кредитов, методы гашения ссуд, способы гашения кредитов, просроченная задолженность.

Современная практика банковского кредитования в РФ по-прежнему сталкивается с серьезными проблемами возвратности банковских ссуд: доля просроченной задолженности по кредитам, предоставленным российскими банками, хотя и медленно, но продолжает расти - с 5,12\% на начало 2017 г. до 5,16 \% на его конец [11, с. 13], что является основным сдерживающим фактором развития кредитования в нашей стране.

Проблема высоких рисков банковского кредитования в стране не находит своего практического решения в течение уже более 10 лет. Это требует обращения внимания не только на практический аспект работы банков с заемщиками, но также предполагает углубленное погружение в проблематику механизмов обеспечения возвратности банковских ссуд.

Преследуя цель минимизировать риски непогашения выданных ссуд коммерческие банки в своей практике применяют различные механизмы обеспечения возвратности кредитов. Но, в нормативно-правовой базе Российской Федерации, регламентирующую их деятельность, отсутствует как единообразная трактовка обеспечения банковского кредита, так и порядок организации механизма их возврата, а упоминаются лишь отдельные способы обеспечения кредитных обязательств [5]. Центральный банк, выступая в качестве надзорного органа, уделяет достаточно пристальное внимание вопросам создания кредитными организациями резервов на возможные потери по ссудам, в то время как, в своих нормативных актах, спускаемых банкам, вопросы обеспечения возвратности кредитов не раскрываются [13].
Наряду с существующими недосказанностями в законодательной базе при всей значимости проблемы обеспечения возвратности кредитов, современная наука о банках и банковской деятельности также еще не предложила единый подход к раскрытию механизмов такого обеспечения. Точки зрения авторов, обращавшихся к данной тематике, расходятся в трактовке содержания обеспечения возвратности банковских ссуд, а механизмы такого обеспечения раскрываются через противоречивые определения отдельных его составляющих - источников, видов, форм, методов и способов обеспечения исполнения кредитных обязательств.

Учитывая вышесказанное, в процессе разработки вопросов гарантийно-залоговых механизмов обеспечения возвратности банковских ссуд первоочередной задачей становится уточнение понятийного аппарата и содержания предмета исследования.

Приведенная ниже таблица систематизирует существующие подходы к характеристике содержания гарантийно-залогового механизма и его составляющих элементов.

Одним из первых авторов, сформулировавших понятие «механизм обеспечения возвратности кредитов» является профессор А.М. Тавасиев [14, с. 309-311]. Он увязывает необходимость существования таких механизмов с рискованностью кредитования, когда в случае повышенного риска для его покрытия нужны дополнительные гарантии возврата, и делает акцент на принудительном характере принимаемых мер. В качестве звеньев данного механизма професcop A.M. Тавасиев выделяет способы выдачи кредитов, источники и процедуры их погашения. 
Гарантийно-залоговый механизм и его содержание

\begin{tabular}{|c|c|}
\hline Автор & Содержание подхода \\
\hline Тавасиев А.М. & $\begin{array}{l}\text { Соблюдение принципа возвратности кредитования неразрывно связано с } \\
\text { использованием особого механизма обеспечения. Он включает в себя спо- } \\
\text { собы выдачи кредитов, а также источники и способы их погашения. Меха- } \\
\text { низм обеспечения возврата ссуд может принимать различные формы в за- } \\
\text { висимости от вида использованных в процессе кредитования источников } \\
\text { погашения ссуд. Они могут быть } \text { первичнылми (доход, выручка, заработная } \\
\text { плата заемщика) и вторичнылм (денежные средства, как полученные в ре- } \\
\text { зультате реализации заложенного имущества, так и обещанные поручите- } \\
\text { лем или гарантом). В зависимости от используемых клиентом банка источ- } \\
\text { ников погашения долга по кредиту, выделяют добровольную форму выпол- } \\
\text { нения заемщиком своих обязательств при использовании им первичных } \\
\text { источников и принудительную, при погашении долга за счет обращения к } \\
\text { вторичным (дополнительным) источникам }\end{array}$ \\
\hline Мамонова И.Д. & $\begin{array}{l}\text { Механизм организации возврата сcуды формируется с учетом мест его } \\
\text { субъектов (кредитора и заемщика) в осуществлении кредитного процесса. } \\
\text { Данный механизм напрямую связан с принципом возвратности ссуд. } \\
\text { Форма обеспечения возвратности кредита - конкретный источник и спо- } \\
\text { соб погашения имеющегося долга, юридическое оформление права креди- } \\
\text { тора на использование кредита, организацию контроля банка за достаточ- } \\
\text { ностью и приемлемостью данного источника на всех этапах кредитного } \\
\text { процесса. } \\
\text { Источники погашения долга - выделяют две категории источников в зави- } \\
\text { симости от используемой формы обеспечения возвратности ссуды: первич- } \\
\text { ные (выручка от реализации продукции, оказания услуг или иной доход и } \\
\text { вторичные. } \\
\text { Способы - залог имущества и прав, уступка требований и прав, гарантии и } \\
\text { поручительства }\end{array}$ \\
\hline $\begin{array}{l}\text { Белоглазова Г.Н. } \\
\text { и Кроливец- } \\
\text { кая Л.П. }\end{array}$ & $\begin{array}{l}\text { Обеспечение кредита является одним из способов снижения риска его невоз- } \\
\text { врата, оно выполняет роль дополнительного источника погашения кредита. } \\
\text { Под ним подразумевается обеспечение по кредиту (заложенное имущество, } \\
\text { денежные средства поручителя или гаранта) }\end{array}$ \\
\hline Коробова Г.Г. & $\begin{array}{l}\text { Реализация на практике принципа обеспечения возвратности кредита свя- } \\
\text { зана с выражением необходимости защиты кредитной организации от фи- } \\
\text { нансовых потерь в случаях нарушения заемщиком своих обязательств, а } \\
\text { также от потери банком активов и прибыли. } \\
\text { Обеспечение возвратности кредита - принцип кредитования, который вы- } \\
\text { ражает необхомиость защиты имущественных интересов банка при воз- } \\
\text { можном нарушении заемщиком принятых на себя обязательств. } \\
\text { В случаях если финансовое положение заемщика банка является неустой- } \\
\text { чивым, то в рамках реализации принципа возвратности ссуд, на практике } \\
\text { применяются формы обеспечения возвратности кредита. Форма обеспече- } \\
\text { ния возвратности банковских ссуд - форма гарантированных обязательств } \\
\text { заемщика. Все виды обязательств, являющиеся обеспечительными, высту- } \\
\text { пают дополнительными к обязательству по основному долгу. К формам } \\
\text { относятся: залог имущества, гарантия, поручительство и другие способы, } \\
\text { закрепленные законом или договором. К источникам возврата ссуд отно- } \\
\text { сятся: выручка от реализации заложенного имущества, средства поручите- } \\
\text { лей, гарантов, страховых обществ и т. д. Источники подразделяются на } \\
\text { первичные и вторичные (дополнительные). К первичным относится доход } \\
\text { заемщика, а ко вторичным - выручка от реализации залога, а также средст- } \\
\text { ва гаранта и поручителя. На практике также возможно одновременное ис- } \\
\text { пользование различных источников }\end{array}$ \\
\hline
\end{tabular}


Окончание таблицьь

\begin{tabular}{|c|c|}
\hline Автор & Содержание подхода \\
\hline Бойко И.А. & $\begin{array}{l}\text { К числу немаловажных элементов кредитования относится его обеспечен- } \\
\text { ность. } \\
\text { В механизм организации возврата кредита включаются: } \\
\text { 1) порядок погашения конкретной ссуды за счет выручки (дохода); } \\
\text { 2) юридическое закрепление порядка ее погашения в кредитном договоре; } \\
\text { 3) использование разнообразных форм обеспечения полноты и своевре- } \\
\text { менности обратного движения ссуженной стоимости. } \\
\text { Форма обеспечения возвратности кредита - конкретный источник пога- } \\
\text { шения имеющегося долга, юридическое оформление права кредитора на } \\
\text { его использование, организацию контроля банка за достаточностью и при- } \\
\text { емлемостью данного источника. } \\
\text { К формам обеспечения относится-залог движимого и недвижимого имуще- } \\
\text { ства, в том числе государственных ценных бумаг, банковские гарантии и дру- } \\
\text { гие способы, предусмотренные федеральными законами и договором. Допус- } \\
\text { кается как использование одной, так и одновременно нескольких форм. } \\
\text { Источники погашения ссуд подразделяются на первичные (доход заемщи- } \\
\text { ка) и вторичные или дополнительные (выручка от реализации заложенного } \\
\text { имущества, перечисление средств гарантом или страховой организацией). } \\
\text { В случае погашения кредита за счет вторичных источников включается в } \\
\text { действие механизм принудительного взыскания причитающегося долга. } \\
\text { Вторичные источники только подкрепляют первичные, но не могут являть- } \\
\text { ся их заменой. } \\
\text { Механизм погашения ссуды - это добровольное выполнение клиентом сво- } \\
\text { их платежных обязательств перед банком, зафиксированных в кредитном } \\
\text { договоре }\end{array}$ \\
\hline Малахова Н.Г. & $\begin{array}{l}\text { К видам обеспечения относятся: залог, гарантия, поручительства, страхова- } \\
\text { ние кредитного риска, переуступка (цессия) в пользу банка требований и } \\
\text { счетов заемщику третьему лицу и др. }\end{array}$ \\
\hline $\begin{array}{l}\text { Мурадова С.Ш. } \\
\text { и Алексеева Е.В. }\end{array}$ & $\begin{array}{l}\text { Механизм организации возврата ссуд учитывает место кредитора и за- } \\
\text { емщика в осуществлении процесса кредитования. Данный аспект вклю- } \\
\text { чает в себя: } \\
\text { 1) порядок погашения конкретного кредита за счет выручки (дохода); } \\
\text { 2) юридическое закрепление порядка погашения в кредитном договоре; } \\
\text { 3) использование различных форм обеспечения полноты и своевременно- } \\
\text { сти обратного движения ссуженной стоимости. } \\
\text { Форма обеспечения возвратности ссуд - конкретный источник погашения } \\
\text { имеющегося долга, юридическое оформление права кредитора на его ис- } \\
\text { пользование, организацию контроля банка за достаточностью и приемле- } \\
\text { мостью данного источника. } \\
\text { Источники погашения кредита подразделяются на первичные (выручка } \\
\text { или доход) и вторичные (залог имущества и прав, уступка требований и } \\
\text { прав, гарантии и поручительства, страхование) }\end{array}$ \\
\hline
\end{tabular}

Примечание. Составлено автором.

Включение в состав механизма обеспечения возвратности ссуд такого составного элемента, как способы выдачи кредитов является отличительной особенностью подхода профессора А.М. Тавасиева. Свою позицию относительно включения данного элемента автор не обосновывает и не уточняет его место в механизме обеспечения. Кроме того, дискуссионной является позиция А.М. Тавасиева относительно жесткого разграничения источников в разрезе определяемых ими форм механизма обеспечения возврата ссуд. Согласно данной точке зрения, первичные источники возврата могут применяться лишь при добровольной форме выполнения заемщиком своих обязательств, а вторичные, лишь при вступлении в силу принудительной формы взыскания задолженности с должника. В этом вопросе не учитываются возможные ситуации, когда кредитная организация в принуди- 
тельном порядке - по решению суда может потребовать списать средства со счета клиента в качестве погашения кредита, или в случае если клиент нарочно создал ситуацию, заложив залог в качестве обеспечения по кредиту с целью его реализации. В таких случаях первичные источники могут быть использованы в рамках принудительной формы взыскания обязательств, а вторичные в рамках добровольной.

Целостностью подхода и глубиной отличается подход профессора И.Д. Мамоновой [2, с. 544-546], согласно которому механизмы обеспечения возвратности взаимосвязаны с основами кредита, и этим механизмам отводится роль прямого инструмента реализации такого принципа кредитования, как обеспеченность. Причиной тому является то, что обязательства, предусмотренные в кредитном договоре не дают полной гарантии его выполнения, и возврат ссуды нуждается в особом механизме обеспечения. Фундаментом механизма обеспечения возвратности ссуд выступает обязательная и одновременная реализация экономических и правовых мер, сопровождающих процесс кредитования. Функционирование такого механизма невозможно без источников возврата кредитов. Среди них автор выделяет первичные и вторичные, а также говорит о соответствующих способах их использования. Раскрывая данные понятия, профессор И.Д. Мамонова уделяет внимание лишь первичным источникам и способам использования вторичных, не раскрывая присущие первичным источникам способы, а также не уделяет внимание уточнению понятия «вторичные источники», что также не дает возможности увидеть полную картину структуры механизма обеспечения.

Г.Н. Белоглазова и Л.П. Кроливецкая в учебнике «Банковское дело. Организация деятельности коммерческого банка» $[1$, с. $74-$ 75] увязывают обращение к вторичным источникам погашения ссуд как реализацию принципа ее обеспеченности, а сами кредиты классифицируют на необеспеченные и обеспеченные. К необеспеченным относят ссуды, которые предоставляются на короткий срок и только заемщикам с первоклассным уровнем кредитоспособности. Ко второму виду ссуд, в связи с повышенным уровнем кредитного риска, относят кредиты, обеспеченные залогом и другими формами гарантии платежа. Каждая форма обеспечения влечет за собой использование какого-либо своего источника возврата ссуды. Стоит отметить, что в подходах к рассмотрению авторами научных основ деятельности банков по обеспечению возвратности кредитов используются термины «виды обеспечения», «формы обеспечения» и «источник погашения кредита», между которыми не проводится четкой грани.

Профессор Г.Г. Коробова [3, с. 322-333] в рамках своего подхода к трактовке основ обеспечения возвратности кредитов считает предпочтительным придавать особое значение первичным источникам. А в случаях, если у кредитора появляются сомнения в возможности их использования для погашения ссуды, автор придерживается позиции вовсе отказать в выдаче ссуды, из-за возможных трудностей, возникающих при взыскании средств в счет погашения долга путем обращения ко вторичным источникам. К числу спорных моментов подхода профессора Г.Г. Коробовой стоит отнести некую путаницу в некоторых определениях. Так, согласно таблице видно, что понятие «форма» отождествляется понятию «способ», что противоречит этимологии данных терминов.

Один из соавторов учебников «Деятельность коммерческих банков» И.А. Бойко [6, с. 105-108] рассматривает обеспечение кредитов как необходимую форму снижения кредитных рисков банков, которая на практике, тем не менее, не является гарантией своевременного возврата долга банку. Автор считает, что механизм погашения ссуды за счет выручки и его юридическое закрепление в кредитном договоре выступает в роли основной предпосылки возврата кредита, а определение форм обеспечения представляет собой гарантию возврата, которая востребована при высокой степени риска невозврата кредита. В этом И.А. Бойко фактически присоединяется к точке зрения, выдвигаемой Г.Г. Коробовой относительно отождествления понятий «формы» и «способы» обеспечения возврата кредита.

Согласно другой известной точке зрения Н.Г. Малаховой [7, с. 47], «форма» и «вид» кредитного обеспечения также по смыслу не отличаются между собой. 
В рамках подхода, предложенного С.Ш. Мурадовой и Е.В. Алексеевой [10, с. 194-198], существование механизма организации возврата кредита увязывается с реализацией принципа возвратности ссуд. В процессе кредитования банк имеет возможность выбора заемщика, размера выдаваемой ссуды, методов ее погашения, а также условий сделки, в процессе осуществления которой создавались бы предпосылки для своевременного и полного возврата выданной взаймы стоимости. В силу того, что наличие у заемщика обязательства вернуть банку долг, не служит гарантией своевременного и полного возврата клиентом денежных средств, был разработан механизм возврата кредита. Основным элементом, обеспечивающим функционирование данного механизма, является форма обеспечения возвратности кредита, которая полностью зависит от используемого вида источника. Авторы делят их на первичные и вторичные. Спорным моментом в концепции С.Ш. Мурадовой и Е.В. Алексеевой является то, что авторы, рассматривая понятие «источники», отождествляют его как с формами, так и с методами обеспечения возвратности ссуд.

Н.А. Мельникова в своем диссертационном исследовании рассматривает обеспечение возврата кредитов как способ минимизации кредитных рисков. Автор определяет обеспечение по кредитам, как один из основных инструментов страхования рисков кредиторов, а также как психологический рычаг воздействия на должника, который будет способен побудить его к своевременному исполнению взятых на себя обязательств. Н.А. Мельникова определяет обеспечение как виды и формы гарантированных обязательств заемщика перед кредитором по возвращению полученного кредита. Также в своей работе автор приводит иное определение, согласно которому обеспечение является составом различных форм и способов обеспечения, а также совокупностью условий. При рассмотрении вопроса классификации обеспечения, автор оперирует понятиями «виды», «формы» и «способы» как тождественными, а последние подразделяет на формы, что говорит о путанице в понятиях. Способы считает неотъемлемым элементом системы риск-менеджмента кредитных организа- ций. Н.А. Мельникова в своем труде соглашается с позицией А.И. Ольшаного, который выделяет традиционные и нетрадиционные способы обеспечения возврата кредита. Подводя итоги, автор дает определение обеспечению возврата банковского кредита, составляющие компоненты которого не находят отражение в исследовании «... это совокупность условий, способов, форм и видов конкретных источников погашения имеющихся обязательств заемщика перед банком, а также юридическое оформление прав кредитора на их использование и организацию контроля банка за достаточностью и приемлемостью данных источников» [8, с. 44].

В научном труде Д.А. Палина [12, с. 14], посвященному одному из составляющих элементов гарантийно-залогового механизма банковской гарантии, опровергается возможность отнесения банковской гарантии к числу финансовых инструментов, автор определяет ее как «исключительно способ обеспечения обязательств».

О.В. Мосолова [9, с. 25] рассматривая вопрос, посвященный проблемам залогового механизма, акцентирует свое внимание на уточнении сути различий между такими вытекающими из залога понятиями как: «форма залога» и «вид залога». Также, автор дает следующее определения: «Залог - это один из способов обеспечения кредитных обязательств» и «Залог - это один из способов, реализующих исполнение должником (залогодателем) принятых на себя обязательств».

Стоит отметить, что согласно данным, приведенным в таблице, прослеживается следующая закономерность. В случае если автор, в рамках своего подхода приводит определение понятию «обеспечение кредита», то он не дает определение понятию «механизм обеспечения возвратности кредита» и наоборот, что позволяет сделать вывод о разности подходов и выявить одно из ключевых различий в них.

Таким образом, можно увидеть из таблицы, что позиции авторов довольно серьезно разнятся, но несмотря на это, мы можем проследить определенную динамику развития данного теоретического вопроса. Особенно явно изменения отражаются на определении понятия «способ обеспечения возврата кре- 
дита». Так, одним из первых, давших определение понятию «способы» стал А.М. Тавасиев, который понимает под ними процедуры погашения ссуд. Позднее выдвигались иные точки зрения, так позиция Г.Г. Коробовой была схожа с позицией И.А. Бойко, в рамках которых, отождествлялись понятия «форма» и «способ» обеспечения возвратности кредита. На наш взгляд определенной целостностью подхода отличается точка зрения И.Д. Мамоновой, в рамках которого, механизм обеспечения возвратности кредитов рассматривается в разрезе его составляющих - форм и источников, а также последние классифицируются на первичные и вторичные.

Проанализировав данные Д.А. Палиным и О.В. Мосоловой определения таких составных элементов гарантийно-залоговых механизмов обеспечения кредитных обязательств, как «гарантия» и «залог», авторы едины во мнении о том, что данные категории являются способами обеспечения обязательств.

В завершении изложения полученных результатов в рамках проведенного исследования содержания, форм, методов, источников, видов и способов механизмов обеспечения возвратности банковских кредитов, можно сделать общий вывод о недостаточной разработанности понятийного аппарата данной сферы кредитной деятельности. В настоящее время это становится препятствием на пути разработки новых обеспечительных механизмов кредитования и решения острых проблем невозврата банковских ссуд [4, с. 264], с какими сталкивается в последнее время Российская банковская система. Проведенное исследование преследовало цель систематизировать имеющиеся в науке подходы к пониманию содержания гарантийно-залоговых механизмов и его составляющих элементов. Данный вопрос требует дальнейшего изучения в части содержательной характеристики описанных механизмов и проработки способов их реализации в современной банковской практике.

\section{СПИСОК ЛИТЕРАТУРЫ}

1. Банковское дело. Организация деятельности коммерческого банка : учебник / под ред.
Г. Н. Белоглазовой, Л. П. Кроливецкой. - М. : Высшее образование, 2008. - 422 c.

2. Банковское дело : учебник / О. И. Лаврушин, И. Д. Мамонова, Н. И. Валенцева [и др.] ; под ред. засл. деят. науки РФ, д-ра экон. наук, проф. О. И. Лаврушина. - 8-е изд., стер. - М. : КНОРУС, 2009. $-768 \mathrm{c}$.

3. Банковское дело : учебник / под ред. Г. Г. Коробовой. - 2-е изд., перераб. и доп. - М. : Магистр, Инфра-М, 2015. -592 с.

4. Богомолов, С. М. Кредитные инновации в банковском бизнесе / С. М. Богомолов, Л. В. Ильина // Известия Российского экономического университета им. Г. В. Плеханова. - 2015. - № 4 (22). C. 263-273.

5. Гражданский кодекс Российской Федерации (часть вторая) от 26.01.1996 № 14-Ф3 (ред. от 18.04.2018). - Электрон. текстовые дан. - Режим доступа: http://www.consultant.ru/document/cons doc_LAW_9027/(дата обращения: 20.04.2018). - Загл. с экрана.

6. Деятельность коммерческих банков : учеб. пособие / А. В. Калтырин [и др.] ; под ред. А. В. Калтырина. - 2-е изд., перераб. и доп. - Ростов н/Д : Феникс, 2005. -400 с. : ил.

7. Малахова, Н. Г. Деньги. Кредит. Банки : учеб. пособие / Н. Г. Малахова. - Ростов н/Д : Феникс, 2007. - 224, [1] с.

8. Мельникова, Н. А. Управление обеспечением возврата банковских кредитов : дис. .... канд. экон. наук: 08.00.10 / Мельникова Наталья Алексеевна ; [Место защиты: С.-Петерб. гос. ун-т экономики и финансов]. -СПб., 2012.-181 с. : ил.

9. Мосолова, О. В. Развитие залогового механизма в системе кредитования : дис. ... канд. экон. наук: 08.00.10 / Мосолова Ольга Викторовна ; [Место защиты: Финансовый ун-т при Правительстве РФ]. - Москва, 2013. - 196 с. : ил.

10. Мурадова, С. Ш. Банковское дело : учеб. пособие / С. Ш. Мурадова, Е. В. Алексеева. - Ростов н/Д : Феникс, 2009. - 256 с.

11. Обзор банковского сектора Российской Федерации (Интернет-версия): Аналитические показатели. Март 2018 г. № 185 // Банк России : Официальный сайт Банк России, 2000-2018. - Электрон. текстовые дан. - Режим доступа: http://www.cbr.ru/ analytics/bank_system/obs_185.pdf (дата обращения: 10.03.2018). - Загл. с экрана.

12. Палин, Д. А. Банковская гарантия как эффективный инструмент развития кредитных отношений : дис. ... канд. экон. наук: 08.00.10 / Палин Дмитрий Александрович ; [Место защиты: Ин-т экономики, права и гум. спец.]. - Краснодар, 2012. -159 с. : ил.

13. Положение Банка России от 28 июня 2017 г. № 590-П «О порядке формирования кредитными 
организациями резервов на возможные потери по ссудам, ссудной и приравненной к ней задолженности». - Электрон. текстовые дан. - Режим доступа: https:/www.garant.ru/products/ipo/prime/doc/71621612/ (дата обращения: 14.05.2018). - Загл. с экрана.

14. Тавасиев, А. М. Банковское дело : учебник для бакалавров / А. М. Тавасиев. - М. : Издательство Юрайт, 2015. - 336 с.

\section{REFERENCES}

1. Beloglazova G.N., Krolivetskaya L.P., eds. Bankovskoe delo. Organizatsiya deyatelnosti kommercheskogo banka [Banking. The Organization of Commercial Bank's Activity]. Moscow, Vysshee obrazovanie Publ., 2008. 422 p.

2. Lavrushin O.I., Mamonova I.D., Valentseva N.I., et al. Bankovskoe delo [Banking]. Moscow, KNORUS Publ., 2009. 768 p.

3. Korobova G.G., ed. Bankovskoe delo [Banking]. Moscow, Magistr; Infra-M Publ., 2015.592 p.

4. Bogomolov S.M., Ilyina L.V. Kreditnye innovatsii v bankovskom biznese [Credit Innovations in Bank Lending]. Izvestiya Rossiyskogo ekonomicheskogo universiteta im. G. V. Plekhanova, 2015, no. 4 (22), pp. 263-273.

5. Grazhdanskiy kodeks Rossiyskoy Federatsii (chast vtoraya) ot 26.01.1996 № 14-FZ (red. ot 18.04.2018) [The Civil Code of the Russian Federation (part two) of 26 January 1996 No. 14-FL (ed. of 18 April 2018)]. URL: http://www.consultant.ru/document/ cons doc LAW 9027/. (accessed 20 April 2018).

6. Kaltyrin A.V., ed. Deyatelnost kommercheskikh bankov [Commercial Banks' Business]. Rostov-on-Don, Feniks Publ., 2005. 400 p.

7. Malakhova N.G. Dengi. Kredit. Banki [Money. Credit. Banks]. Rostov-on-Don, Feniks Publ., 2007. 224, [1]p.
8. Melnikova N.A. Upravlenie obespecheniem vozvrata bankovskikh kreditov: dis. ... kand. ekon. nauk [Management of Bank Credits' Return. Cand. econ. sci. diss.]. Saint Petersburg, 2012. 181 p.

9. Mosolova O.V. Razvitie zalogovogo mekhanizma $v$ sisteme kreditovaniya: dis. ... kand. ekon. nauk [Development of Mortgage Mechanism in the System of Crediting. Cand. econ. sci. diss.]. Moscow, 2013. 196 p.

10. Muradova S.Sh., Alekseeva E.V. Bankovskoe delo [Banking]. Rostov-on-Don, Feniks Publ., 2009. $256 \mathrm{p}$.

11. Obzor bankovskogo sektora Rossiyskoy Federatsii (Interner-versiya). Analiticheskie pokazateli. Mart 2017 goda. № 185 [Review of the Banking Sector of the Russian Federation (Internet Version). Analytical Indicators. March 2017. No. 185]. Bank Rossii: Ofitsialnyy sayt Bank Rossii, 2000-2018 [Bank of Russia. Official Website, 2000-2018]. URL: http:// www.cbr.ru/analytics/bank_system/obs_185.pdf. (accessed 10 March 2018).

12. Palin D.A. Bankovskaya garantiya kak effektivnyy instrument razvitiya kreditnykh otnosheniy: dis. ... kand. ekon. nauk [A Bank Guarantee as an Effective Instrument of Credit Relations. Cand. econ. sci. diss.]. Krasnodar, 2012. 159 p.

13. Polozhenie Banka Rossii ot 28 iyunya $2017 \mathrm{~g}$. № 590-P «O poryadke formirovaniya kreditnymi organizatsiyami rezervov na vozmozhnye poteri po ssudam, ssudnoy $i$ priravnennoy $k$ ney zadolzhennosti» [Regulation of the Bank of Russia of June 28, 2017 No. 590-P 'On the Procedure for the Formation by Credit Organizations of Reserves for Possible Losses on Loans, Loan and Equivalent Debts']. URL: https:// www.garant.ru/products/ipo/prime/doc/71621612/. (accessed 14 May 2018).

14. Tavasiev A.M. Bankovskoe delo [Banking Business]. Moscow, Yurayt Publ., 2015. 336 p.

\section{Information about the Author}

Kira V. Smetanina, Postgraduate Student, Department of Banking, Money and Credit, Saratov Socio-Economic Institute (Branch) of Plekhanov Russian University of Economics, Radishcheva St., 89, 410003 Saratov, Russian Federation, kirasmetana@mail.ru.

\section{Информация об авторе}

Кира Владимировна Сметанина, аспирант кафедры банковского дела, денег и кредита, Саратовский социально-экономический институт (филиал) Российского экономического университета им. Г.В. Плеханова, ул. Радищева, 89, 410003 г. Саратов, Российская Федерация, kirasmetana@mail.ru. 